University of Nebraska - Lincoln

DigitalCommons@University of Nebraska - Lincoln

Faculty Publications, Department of Child, Youth, and Family Studies

Child, Youth, and Family Studies, Department of

2007

\title{
Providers' Perspectives on Troublesome Overusers of Medical Services
}

\author{
Richard Bischoff \\ University of Nebraska-Lincoln, rbischoff2@unl.edu \\ Cody S. Hollist \\ University of Nebraska Lincoln, chollist2@unl.edu \\ JoEllen Patterson \\ University of San Diego \\ Lee Williams \\ University of San Diego \\ Layne Prest \\ University of Nebraska Medical Center \\ See next page for additional authors
}

Follow this and additional works at: https://digitalcommons.unl.edu/famconfacpub

Part of the Family, Life Course, and Society Commons

Bischoff, Richard; Hollist, Cody S.; Patterson, JoEllen; Williams, Lee; Prest, Layne; and Barkdull, Matthew D., "Providers' Perspectives on Troublesome Overusers of Medical Services" (2007). Faculty Publications, Department of Child, Youth, and Family Studies. 68.

https://digitalcommons.unl.edu/famconfacpub/68

This Article is brought to you for free and open access by the Child, Youth, and Family Studies, Department of at DigitalCommons@University of Nebraska - Lincoln. It has been accepted for inclusion in Faculty Publications, Department of Child, Youth, and Family Studies by an authorized administrator of DigitalCommons@University of Nebraska - Lincoln. 


\section{Authors}

Richard Bischoff, Cody S. Hollist, JoEllen Patterson, Lee Williams, Layne Prest, and Matthew D. Barkdull 
Published in Families, Systems, \& Health 25:4 (2007), pp. 392-403; doi 10.1037/1091-7527.25.4.392

Copyright ( 2007 American Psychological Association. Used by permission. "This article may not exactly replicate the final version published in the APA journal. It is not the copy of record."

\title{
Providers' Perspectives on Troublesome Overusers of Medical Services
}

\author{
Richard J. Bischoff, Marriage and Family Therapy Program, University of Nebraska-Lincoln \\ Cody S. Hollist, Department of Child, Youth and Family Studies, University of Nebraska-Lincoln \\ JoEllen Patterson, Marital and Family Therapy Program, University of San Diego \\ Lee Williams, Marital and Family Therapy Program, University of San Diego \\ Layne Prest, Department of Family Practice, University of Nebraska Medical Center \\ Matthew D. Barkdull, LDS Family Services \\ Corresponding author - Richard J. Bischoff, Marriage and Family Therapy Program, \\ University of Nebraska-Lincoln, P.O. Box 830801, Lincoln, NE 68583-0801, \\ email rbischoff2@unl.edu
}

\begin{abstract}
The purpose of this study was to better understand providers' perspectives of and experiences with frequent users of medical services. Focus group interviews were conducted with physicians in San Diego, California, and Omaha, Nebraska. Indicators of problematic patient overuse of medical services were identified as well as the common physician experience of overuse that is troublesome and problematic. Qualitative data analysis revealed that physicians did not consider patient overuse, by itself, to be problematic. Overuse became problematic and troublesome when patient behavior violated the physician-patient relationship of trust. All participants described a distinct negative physiological reaction to these patients.
\end{abstract}

Keywords: Difficult patients, high utilizers, medically unexplained symptoms, doctor/ patient relationship, health care utilization
T $t$ has long been known that the major1 ity of health care resources go toward the treatment of the minority of patients (Hahn, Thompson, Wills, Stem, \& Budner, 1994; Suchman, Roter, Green, et al., 1993; Wagner \& Hendrich, 1993). We assume that most high users need the medical services they receive because of chronic medical conditions that require vigilant, frequent, and at times aggressive medical attention. However, a minority of frequent users have symptoms that are not readily attributed to organic causes, and many of these patients receive or use services that are not medically indicated (Hahn et al., 1994; Kroenke \& Laine, 2001; Kroenke \& Mangelsdorff, 1989; Suchman et al., 1993). "Medically unexplained symptoms" are often associated with patient distress and impaired functioning (Kroenke \& Harris, 2001) and are commonly seen in primary care (Kroenke \& Mangelsdorff, 1989). The presentation of medically unexplained symptoms can be a source 
of frustration for both physicians (Katon \& Walker, 1998; Schwenk \& Romano, 1992; Sharpe et al., 1994; Walker, Unutzer, \& Katon, 1998) and patients (Hays, Cunningham, Ettl, Beck, \& Shapiro, 1995; Jackson \& Kroenke, 2001) and can result in misdirected or inappropriate use of medical care (Kravitz, 2001; Jackson \& Kroenke, 2001).

It has been found that up to three quarters of the physical symptoms for which patients present at primary care offices do not have identifiable organic causes (Kroenke \& Mangelsdorff, 1989). Kroenke and Harris (2001) explain that the quality of the physician-patient relationship is particularly important when working with patients presenting with medically unexplained symptoms. Regardless of cause, patients come to treatment to seek relief and reassurance (e.g., Jackson \& Kroenke, 2001; Kroenke \& Mangelsdorff, 1989; Kroenke \& Harris, 2001; Walker, Unutzer, \& Katon, 1998). They expect the physician to provide a diagnosis, a prognosis, and to take some action (Jackson \& Kroenke, 2001). When this does not happen, the stage is set for patient dissatisfaction and overuse of medical services (see Kravitz, 2001; Jackson \& Kroenke, 2001).

Distinguishing between appropriate use and overuse of medical services is particularly complex and challenging. Patients, providers, and the context in which medical care is provided can all drive overuse. Judgments of overuse are informed by the person's role in the health care system. Physicians, mental health therapists, patients, administrators, and others will all have different perspectives on what constitutes overuse of medical services and the implications of overuse for medical care.

The purpose of this study was to develop a greater understanding of patient overuse of medical services from the perspective of the medical provider. Understanding how providers conceptualize, determine, and experience overuse may shed light on how they approach and deal with "difficult" patients. It may also lead to suggestions for treating patients within the context of the reasons for why they are seeking treatment.

\section{Methods}

\section{Data Collection}

Health care providers were recruited for participation from two health care networks, one in San Diego, California, and the other in Omaha, Nebraska. The 17 participating health care providers in San Diego, California, were affiliated with the three Sharp Health Care (SHC) family practice residency program clinics. The 13 participating physicians in Omaha belonged to the University Medical Associates (UMA) physicians' network associated with the University of Nebraska Medical Center (UNMC). Participants were recruited from three Omaha area UMA clinics. All participants except one (a nurse practitioner affiliated with SHC) were physicians. One of the four focus groups with SHC was composed of residents. All other participants were experienced physicians. Of the 17 SHC participants, 11 were female. Of the 13 UMA participants, 6 were female.

Focus group interviewing was chosen as the data collection strategy (Morgan, 1993). Focus group interviewing allowed us to bring together those with experience in working with frequent users to work toward a consensual description based on common experiences. Focus groups consisted of four to five participants. All focus group interviews were audiotaped and transcribed for data analysis.

Four focus groups were conducted at SHC clinics in 1996, but after a preliminary analysis of these data, three focus groups with UMA were added in 2000 in order to achieve saturation. UMA was chosen as a site for the additional focus groups because (a) both SHC and UMA had medical family therapists on site and emphasized collaborative care practice and (b) regional differences in the locations of the clin- 
ics would help to determine the stability of the findings. Similar themes as those identified at $\mathrm{SHC}$ were identified through the focus groups conducted at UMA. This was taken as evidence of data saturation or the point at which more information ceases to produce new knowledge but merely confirms what has already been understood.

Each focus group loosely followed a preconceived structure in order to keep the discussion on task. The structure was organized around questions designed to help the interviewer elicit information and facilitate consensus. For example, in order to reduce the possibility that the interview would result in just a discussion of problem patients, interviewers first asked participants to reflect on their clinical experience and to describe patient frequent use of medical services. This general question resulted in conversations about both appropriate and overuse of medical services. The focus group interviews then progressed to determining the common signs or indicators of patient overuse, reasons for overuse, and the consequences of overuse. Interviewers facilitated a discussion that encouraged interaction among focus group participants by asking them to comment and build on statements and experiences shared by others. In this way, the discussion of frequent use of medical services built throughout the interview, with every participant having an opportunity to contribute to refining the description of frequent users of medical services.

\section{Investigators}

The investigators brought to bear a variety of experience in working with medical providers. This facilitated looking at the data and reconstructions of the data from multiple perspectives, thereby increasing the confidence that can be placed in the results. Two investigators were on the clinical faculty at SHC and one was on the clinical faculty at UMA. As mental health therapists, they provided training and consultation to medical residents on mental health issues and collaborative care practice strategies. They also consulted with medical faculty and staff on mental health issues and provided collaborative care treatment and psychotherapy to patients seen at the clinics. Among the other three investigators, one was a mental health therapist at UMA and the other two were family therapists not affiliated with either clinic, but with experience providing mental health and collaborative care treatments.

Two of the investigators conducted the focus group interviews. One conducted three focus groups at SHC and the other conducted one at SHC and three at UMA. The interviewer for each focus group was an investigator who did not have experience working in the clinic from which the participants were drawn. This was done to eliminate the influence of being interviewed by a colleague. To ensure continuity of the interviews, one interviewer sat in on, but did not participate in, the other three focus groups, even though he had experience working with the participants in these interviews. At the conclusion of each interview, this investigator created a memo in which he documented his observations of the interview, his impressions of emerging themes, and questions that were raised in the interview that needed to be explored through future interviews and the data analysis. This investigator and another not involved in data collection were primarily responsible for the data analysis.

\section{Data Analysis}

Transcripts of focus group interviews were analyzed using qualitative analytic methodology. Memos generated after each interview informed the analysis of the transcripts. Additional memos were created throughout the analysis of the data to assist in documenting investigator impressions and emerging themes, to facilitate decision making about the direction of the study, and to track progress toward data saturation. Because focus group interviewing emphasizes the evolution of a con- 
versation toward a group consensus, care was taken in data analysis to ensure that the results reflected the outcome of the group discussion, not individual opinions, perceptions, or experiences. We acknowledge that the data presented below supporting the results were statements made by individual participants. But these data were chosen because they best represent the outcomes of the chronological development of the ideas within the group discussion that lead to the results derived from the data analysis.

Both within- and between-case analyses of the transcripts were conducted using open and axial coding (Strauss \& Corbin, 1998). Because focus group interviews result in an evolving discussion where participants move toward a common understanding of the phenomenon, care was taken in analysis to follow the conversation as it evolved. Open coding was used to accomplish this analytic task. Participants' statements were analyzed and coded to represent the meaning of the statement conveyed. Using a constant comparison method (Strauss \& Corbin, 1998), statements were compared and coded together when the meanings of the statements appeared similar. In an effort to capture the richness and diversity of participants' statements across interviews, care was taken during this phase of the data analysis to emphasize the diversity of statements made without prematurely reducing the coding categories. Axial coding was then used to make comparisons across categories. This was a process of linking and combining related categories resulting in an elegant and parsimonious description of high use of medical services.

\section{Results}

In each focus group, participants carefully explained that most frequently using patients received care consistent with their level of medical need. While they volunteered that the medical system is responsible for some overuse (mainly to protect against liability and litigation), they agreed that patient-driven overuse is more likely to be problematic. However, as primary care providers, they expect patients to present for a variety of reasons, many of which are medically unexplained and medically unnecessary. Rather than a general discussion of overuse of medical services, each focus group moved quickly to discussion of the minority of patients that they felt overused medical services in ways that were problematic, and consequently troublesome for them.

\section{When Patient Overuse Becomes Problematic and Troublesome}

Working with patients who chronically overuse medical services requires more time, resources, and effort-which are already in short supply - from everyone involved in care with few discernable positive health outcomes. Participants explained that the pace of the office slows when frequently overusing patients have appointments. This impacts everyone's work. Participants agreed that provider morale is at risk when dealing with frequently overusing patients, and they expressed concern that low morale could compromise patient carenot only for the chronic overuser but for other patients as well.

While acknowledging that not all overuse is problematic, participants across focus groups agreed that they suspect overuse is problematic when it meets one or more of the following three objective criteria: (a) the patient repeatedly accesses the medical system for medically unexplained reasons despite the physician's attempts to educate, reassure, redirect and diagnose; (b) the patient repeatedly attempts to access medical resources that do not match their medical needs; and (c) the patient does not follow through with treatment recommendations and referrals despite the physician's efforts to get them to do so.

While acknowledging that patients meeting one or more of these criteria are difficult to treat, they actively shunned the use of pejora- 
tive labels to describe these patients. Instead, consistent throughout the interviews was an expression of concern for patient welfare and an overtly expressed desire to meet patients' needs. With the exception of the frustration in dealing with those that intentionally manipulated the medical system through deceit or fraud, participant expressions of frustration appeared due to a recognition that the physician was unable to provide relief of patient distress or meet patient needs. They came to agree that most frequent overuse is motivated by real, although often medically unexplained patient distress. They explained that because the distress is real, these patients continue to return to the medical system, and the physician in particular, for relief. One physician summarized for the group:

The frequent users are coming in here to get something from us, and it's usually the physician they are trying to get something from, to solve it for them. I don't think the patient can even put their finger on what it is that needs to be solved. But they want that doctor to fix it for them.

Each of our participants expressed that the real reward in being a primary care physician is in helping people. Frustration results when they realize that the patient presents with something that defies their best efforts to help.

I think part of the frustration comes in because we are doing this profession to make people better, and I am always much happier when I see something come in that I can do something about. If I know I can do an intervention, [if] I can make this well, I'm happy because I feel like I have done something good. The patient is happy. They are feeling like I helped them. The frustrating ones are the ones that you know you are not going to make [a difference with no matter what you do]. That's frustrating, I think. There are patients that I cringe when I see their name on my schedule because I know darn well that they are going to be the same complaints that I couldn't fix a week ago and I couldn't fix a month ago, and I have nothing new to offer. We like to be successful.

\section{When Problematic Overuse Becomes Troublesome}

Our participants explained that they knew that problematic patient overuse was troublesome when they experienced an unmistakable uneasy feeling in the gut, chest, or throat. Agreement was quickly achieved that this negative reaction is the most reliable indicator of problematic and troublesome patient overuse of services. One participant explained, "For these folks who are inappropriate utilizers, it is a gut check. As soon as my gut wrenches and I don't want to see the name, then that is my trigger." Another participant explained, "You feel this clutch [putting her hand across her abdomen] and you know this person is a person that's needy." In a descriptive way, one physician explained that she was treating

this lady who is 50 something and has significant chronic medical problems that definitely have a psychologic overlay...that is making them a lot worse... . She comes in every two weeks... I try to space out the visits, but I have just not been successful. She is probably one of the most uncomfortable visits that I have to deal with in terms of patients. I mean, I look at her name on the schedule and its like, "Oh! I'm seeing her today," because I have nothing to say. I have nothing. I can't help her. I've done everything that I can. The subspecialists have done everything they can... . Yet, she wants to come in and see me every two weeks to hear I don't know what.

The intensity of the frustration experienced in working with these patients was often intense, as is demonstrated in the following com- 
ment made by one of the more experienced physicians.

Nothing works with these people. Your patience level has to be pretty high to deal with it. But I think it's a big help when you recognize... that this is what you're dealing with. Then you use every little trick you've got but also accept the fact that it's not going to be the end of the story. I mean, your only relief is when they actually leave your practice.

Participants said they worried that the intensity of their frustration could result in compromised care for the patient. They were concerned that as morale decreased, providers might become less attentive to patient well-being and more protective of their time and resources. They expressed that in such cases it would be very easy to overlook what would help the patient, unwittingly making the situation worse.

Trust as the Foundation for Good Primary Medical Care

Participants in each focus group were asked to speculate on why they felt they had a negative physical reaction to some patients who overuse medical services and not to others. After discussion, participants in each focus group arrived at the conclusion that it is driven by patient behaviors that undermine trust in the physician-patient relationship. Participants explained that a relationship of trust is at the heart of successful primary care. The patient needs to be able to trust that the physician is knowledgeable and skillful and that they will judiciously bring all available medical resources to bear that are appropriate for providing relief of patient distress and improving health. Likewise, physicians must be able to trust that patients are presenting real distress and that they will do their best to manage their health and follow through with treatment recommendations. One participant explained,
We work in a system of trust. I expect what you are telling me is the truth and what I am going to tell you is the truth, so when you come in and tell me you are having a terrible pain, our nature is that we believe you, we want to help your pain go away.

Our participants explained that they begin with each patient by assuming that they are accessing the medical system in a trustworthy manner; that each patient is honest about what is ailing them, that they are seeking care for problems that the physician can help them with, and that they will accept the limitations of medicine and what the physician is able to give. Troublesome overuse occurs when patients violate this trust. The participant quoted above went on to say,

[Because we inherently trust patients] we are just set up to be suckered. And, we get suckered... . And that happens and I accept that as part of what we do. I would rather get burned and give somebody 10 Vicodin that they really don't need than send somebody out of here being miserable all night. I can live with doing that, but they are still frustrating because you know they keep coming back and it is not necessary.

\section{What Breaches Trust}

Participants identified patient behaviors that they felt breached trust and lead to troublesome patient overuse. These behaviors fall into two categories: (a) a deliberate, conscious manipulation of the medical system and (b) repeated attempts to get something from the physician that they are not able to provide.

\section{Deliberate Manipulation of the Health Care System}

Participants agreed that there is a small group of overusers that engage in manipulative attempts to get some medically unnecessary benefit. They reported that this group was the most distressing group of overusers. These 
patients sought care for reasons such as narcotics or other medications, "a tax deduction on a new jacuzzi," or "a day off work" or school. While these patients will often have some health related problem, it does not warrant what they are asking for. Some present with no real health-related problem, but consciously fain illness to get something from the physician. The commonality among these patients is that they present themselves to the physician with a conscious, but secret agenda, manipulating the system to meet that agenda. On finding out that they have been "suckered," physicians experience frustration and distrust. This distrust results in the uneasy feeling; the gut check that physicians get when they work with these patients.

\section{Trying to Get Something From the Physician That} They Are Not Able to Provide

A need for chronic reassurance. Many patients have trouble evaluating their own health status and need education and reassurance about their health. The participants recognized that providing education and reassurance was an important and necessary part of medical care. Troublesome overuse occurred when patients repeatedly presented with a chronic need to be reassured of their health status despite physician attempts to educate and provide reassurance. Two types of patients were identified. The first type was those they identified as the "worried well or the worried not barely sick... . Someone who has a sniffle and...they're in the doctor's office rather than waiting to see what happens in a day or two." While they did not see the initial, or even the occasional visit of this variety to be problematic, it became troublesome overuse when it was part of a pattern of similar repeated visits in which reassurance and education were not sufficient.

The second type includes small percentage of patients who have chronic, and often lifethreatening medical conditions. Because they are worried about their health status, they will often request medical attention for even slight variations in their symptomotology. The following example illustrates this.

[For] a lot of my HIV patients, every...day [there are] things they consider very significant because they're not sure what it's going to mean... . They think its...life threatening... . I have an HIV patient who probably sees me an average of every 10 days for something. [For example, he says] his rectum is opening and I look at his rectum and there's nothing there. [So 10 days later he calls to say] he has hemorrhoids. I look at him but I don't see anything... . He just thinks he's gonna die from [something].... So, if I were to generalize, people who have serious chronic diseaseand I'm going to put chronic pain as part of that-when there's a change, when there's something new, they don't know what to make out of it. So they magnify it.

A need for social contact and support. Participants explained that many of their troublesome overusers are lonely and lack adequate social support. Many of these patients turn to their physicians for someone to talk to and social support. For example, in describing troublesome visits with some geriatric patients, one participant explained, “ ...they live in nursing homes or they live alone, and they need to have that person-to-person interaction. Ninety percent of the time I'm not doing anything for them. They're just coming because they really want to see my face." Another participant added, "Just making an appointment and going to an appointment gives them something to do." In another focus group, a participant said the following about troublesome visits with other patients who schedule with physician for social reasons: "I have some medical patients that will come in every month. They will make up a reason to come. They just want to sit there 
and talk to me." In yet another group the following example was given.

[Patients like this] don't know anybody so they think you are their friend. They come in for aspirin [but they really want] social support... . They feel extra close to you and for that reason they make frequent visits just to make sure that things are going ok and to ask you questions and stuff.

Psychopathology. Participants agreed that psychopathology drives much of the troublesome patient overuse. One provider said, "I think that a lot of the subset is populated by people with emotional illness." While it was recognized that the distress caused by mental illness is a legitimate reason for seeking care, these patients were often considered troublesome overusers when they would not accept the psychological explanations for their somatic symptoms, would not follow recommendations, and/or when they continued to seek medical care beyond what the physician was able to provide. On participant summarized a discussion about psychopathology by saying,

[You] try to tell them this may be an emotional or just a very stressful circumstance [and they] are very unwilling to accept that explanation and are insisting that there is something wrong....and if you check out one organ system it is not long before a different organ system starts acting up. And you are just constantly chasing these will-of-the-wisp type complaints, and all the while the patient is just unwilling to even consider the possibility that this could be stress or anxiety.

Because mental health problems are seen so frequently in primary care, participants lamented that they did not have more resources and expertise to assess and treat psychological and emotional distress. They felt that this lack of in-house mental health resources and expertise was a primary factor contributing to the problem of troublesome and problematic overuse of medical services. All participants reported that they regularly make referrals to behavioral health, including to medical family therapists practicing in-house, but that many patients with mental health problems do not accept a referral and continue to try to get their needs met through the physician. They pointed out that this was the point at which it became overuse of services. Each focus group described this reluctance to receive mental health care as an avoidance of underlying issues. One participant said,

\begin{abstract}
[A] mental health provider is going to make them deal with the sensitive underlying issues that they may not want to deal with at all. [They would] rather just deal with the symptoms. They want care for their symptoms rather than their underlying life.
\end{abstract}

\section{Discussion}

We found that the negative visceral reaction of the physician is the primary indicator of problematic and troublesome patient overuse of medical services. Participants explained that objective indicators have little practical value because they do not capture the complexity and nuances of patients' experiences with illness, the medical care that they seek, and the experience of the physician in meeting their expectations and addressing their needs. Although certain patient behaviors (i.e., deliberate manipulation, repeatedly using medical visits for reassurance and social support, failing to follow through with recommendations for addressing psychopathology) were identified as contributing to troublesome overuse, physicians did not consider patient use of services troublesome until it violated the trust between the physician and patient, which is the foundation of the physician-patient relationship.

As clinicians gain experience, an intuitive way of knowing manifests itself though phys- 
iological reactions to situations (Epstein, 1999, 2003; Matthews, 2004; Gendlin, 2000). Attending to one's own physiological experience in a clinical situation can become an important piece of data that informs clinical decisionmaking. Clinicians may or may not be able to point to observable indicators as evidence for their decision; rather, they know it because they feel it. It is a way of knowing by attending to the body (Epstein, 1999, 2003). Our research suggests that in identifying problematic overusers, physicians "listen" to their gut. The negative physiological reaction is an intuitive response to patient behavior that is informed by clinical experience.

Clinicians who do not attend to their physiological experience or who dismiss it may miss data important to clinical decision-making. It may also be that these clinicians run the risk of allowing these negative physical symptoms to worsen with negative consequences both for the physician and patients. In the early 1990s, James and Melissa Griffith (1994) wrote a helpful book entitled, The Body Speaks, in which they describe the inseparable, but often overlooked, connection between the mind and the body. They explain that the development of somatic symptoms is a common reaction to stress. They explain that negative physiological symptoms may be pronounced when people find themselves in "unspeakable dilemmas" - when they cannot put into words their concerns for fear of what it would mean to do so. While Griffith and Griffith were writing about patients, this mind-body hypothesis may also apply to clinicians. Could it be that an unspeakable dilemma emerges for physicians when patients, either wittingly or unwittingly, act to undermine the trust that should exist in the physician-patient relationship? If so, this could account for the characteristic visceral reaction to these patients. It may be that an unspeakable dilemma emerges as physicians - who enter the field with a sincere desire to help people, who are trained to do so and who believe that they can be successful-are faced with a pa- tient who presents with something that defies their best attempts to apply all that medicine has to offer.

It is noteworthy that it is a negative physiological response that physicians get and one that could easily be interpreted as a sign of distress. Is it any wonder that pejorative labels have been used to describe difficult and frustrating patients (e.g., Groves, 1978; Katz, 1996; Lipsitt, 1970; Martin, 1975)? However, it is equally noteworthy that our participants were careful to describe their compassion for their patients, even those they considered troublesome overusers. They were careful to explain that even these patients, although perhaps misguided, were experiencing distress and were looking to the medical system for answers, reassurance, relief, and help. With the exception of those who deliberately deceive, our participants continued to talk about these patients positively and with hope that they would at some point figure out how to more effectively work with them. This positive view of overusing patients is a paradigmatic shift from views of the past that have seen overusers as a thorn in the side of the physician. Seeing difficult patients as driven by a legitimate need that they are trying to meet through the medical system makes it possible to engage in conversations about how patient needs can be met and how the culture of medicine can improve the health outcomes of all patients. However, this could also be the root of an unspeakable dilemma for physicians. The inherent compassion and good will of physicians may be challenged by patients who continue to present for medically unexplained reasons despite their best attempts to help them get the care they will need to relieve their distress. These patients exceed their capacity to help and do not do what needs to be done to get the relief that they desire. What does it mean to a physician who has such compassion for patients and who is faced with a patient that they do not want to see and that they may not like? 


\section{Implications for Medical Family Therapists and Collaborative Health Care}

These findings suggest that it is important for physicians to acknowledge their physiological response to patients. Epstein $(1999,2003)$ has suggested that to do so is an important ingredient to mindful practice. Clinicians who are mindful can learn to interpret their physiological responses to clients in a way that results in improved clinical outcomes. In the case of troublesome overusers, the negative visceral reaction to these patients might be used as data leading physicians to ask what it is about either the patient or themselves that is resulting in this type of reaction. Doing so could lead to the use of positive diagnosis strategies such as the BATHE interviewing technique (Stuart \& Lieberman, 2002) that may help to diagnose underlying mental health and other psychosocial conditions that may be contributing to the problematic overuse of the medical system. It could also lead to the development of unique alternative strategies for working with the patient. This could be particularly important in those cases where a patient is presenting with conditions requiring frequent medical attention while at the same time behaving in a way that breaches the relationship of trust. Attending to the negative visceral response might help physicians partial out what it is about the patient that they are reacting to so that they can continue to provide the level of care that is needed.

Mental health therapists working in collaborative care environments are a resource to both physicians and patients (see McDaniel, Hepworth, \& Doherty, 1992; Seaburn, Lorenz, Gunn, Gawinski, \& Mauksch, 1996; Patterson, Peek, Heinrich, Bischoff, \& Scherger, 2002). Consulting with mental health therapists can help physicians acknowledge and interpret their negative visceral reactions to troublesome overusers. A therapist trained in medical family therapy may be able to help identify underlying psychological and relational motivations for medical care seeking behavior and develop treatment plans that take into account the physician experience of the patient and patient and family needs.

It is probable that in some cases physicians unwittingly contribute to troublesome patient overuse. Personality, life stress, and other physician characteristics can all influence how the physician responds to a given patient and how the patient responds to the physician. This interaction can either increase or decrease the probability that problematic overuse will be exacerbated and perhaps even develop into a troublesome physician-patient interaction. Medical family therapists can assist physicians in recognizing and monitoring their own contribution to problematic and troublesome physician-patient interactions.

Doherty, McDaniel, and Baird (1996) identified levels of collaborative care, with the highest level being one where medical care and mental health care are fully integrated within the same health care facility. It may be that collaboration at this highest level is more effective in working with troublesome overusers because the complex interplay of ailments covering the spectrum of the biopsychosocial model (Engel, 1977, 1980) may be able to be addressed more efficiently. Medical family therapists' more active involvement in the care of troublesome overusers may be warranted and may result in improved health care outcomes.

\section{Limitations}

Determinations of overuse are dependent on the role of the individual in the treatment process. Through this study, we have attempted to describe the overuse of medical services from the perspective of the primary care provider. Had we accessed the perspective of people with other roles in the medical system, the descriptions might have been different. For example, physicians participating in this study suggested that the entire pace of the office slows when an overuser is in the clinic, suggesting that the work of office staff, nursing personnel, medical assistants, and others in the clinic 
is also impacted by the overuse of medical services. Their perspectives would enrich the understanding of the problem and would contribute to solutions for meeting the needs of the overuser. Patients, especially frequent users of medical services, would also have a perspective of overuse that would contribute valuable information to understanding overuse and to the development of treatment strategies for improving patient outcomes. In related research, patients' perceptions have yielded important findings about illness and treatment (e.g., Orfali \& Anderson-Shaw, 2005; Peters, Abu-Saad, Vydelingum, Dowson, \& Murphy, 2004).

Unfortunately, the interviewers did not confirm with participants whether the physiological response they identified was a literal or a figurative description of their experience. However, assuming that the mind-body hypothesis is correct, we can assume that it is both literal and figurative. But this is something that would need to be addressed in future research. In the mean time, to describe this reaction as visceral would be appropriate because this term refers to both the physiological and the intuitive experience described by participants.

The reader should also be aware that there might have been other factors related to the design of this study that limit the application of the results. First, while the focus group interview format of data collection has the advantage of allowing discussion to build toward consensus, it may have also have the effect of discouraging dissenting opinion or ideas that may not have been consistent with the direction of the discussion. One of the noteworthy findings in this study is that participating physicians had a surprisingly optimistic and positive view of high utilizing patients. This view was consistently represented even despite unequivocal statements about being frustrated and discouraged when working with these patients and previous literature in which is found pejorative characterizations of these patients. It is possible that this positive perspective is an artifact of the focus group, in which partici- pants are well aware that their colleagues are hearing their comments and opinions. Second, the investigators' involvement with the clinics from which participants were sampled may have introduced a bias into both the data collection and the analysis, which may not fully represent the perspectives of the participants.

Despite these limitations, this and similar research can contribute to attempts to increase health outcomes for patients who are frequent users of medical care services. We recommend that future research investigate more fully patient motivations for accessing medical care. The results of these studies could help increase the accuracy of assessment of patient needs and provide direction for better meeting those needs. We expect that studies such as these will lead to the more efficient and effective use of health care resources, improved patient outcomes, and greater patient and provider satisfaction with treatment.

\section{References}

Doherty, W. J., McDaniel, S. H., \& Baird, M. A. (1996). Five levels of primary care/behavioral healthcare collaboration. Behavioral Healthcare Tomorrow, 5, 25-27.

Engel, G. L. (1977). The need for a new medical model: A challenge to biomedicine. Science, 196, 129-136.

Engel, G. L. (1980). The clinical application of the biopsychosocial model. American Journal of Psychiatry, 137, 535-544.

Epstein, R. M. (1999). Mindful practice. Journal of the American Medical Association, 282, 833-839.

Epstein, R. M. (2003). Mindful practice in action (I): Technical competence, evidence-based medicine, and relationship-centered care. Families, Systems $\mathcal{E}$ Health, 21, 1-9.

Gendlin, E. T. (2000). The "mind" /"body" problem and first person process: Three types of concepts. In R. D.Ellis \& N.Newton (Eds.), The caldron of consciousness: Motivation, affect and self organization (pp. 109-118). Amsterdam, Germany: John Benjamins Publishing Company.

Griffith, J. L., \& Griffith, M. E. (1994). The body speaks. New York: Basic Books.

Groves, J. E. (1978). Taking care of the hateful patient. New England Journal of Medicine, 289, 883-887. 
Hahn, W. R., Thompson, K. S., Wills, T. A., Stem, V., \& Budner, N. S. (1994). The difficult physician-patient relationship: Somatization, personality, and psychopathology. Journal of Clinical Epidemiology, $47,647-657$.

Hays, R. D., Cunningham, W. E., Ettl, M. K., Beck, C. K., \& Shapiro, M. F. (1995). Health-related quality of life in HIV disease. Assessment, 3, 363-380.

Jackson, J. L., \& Kroenke, K. (2001). The effect of unmet expectations among adults presenting with physical symptoms. Annals of Internal Medicine, 134, 889-896.

Katon, W. J., \& Walker, E. A. (1998). Medically unexplained symptoms in primary care. Journal of Clinical Psychiatry, 59, 15-21.

Katz, R. C. (1996). "Difficult patients" as family physicians perceive them. Psychological Reports, 79, 539-544.

Kravitz, R. L. (2001). Measuring patients' expectations and requests. Annals of Internal Medicine, 134, 881-888.

Kroenke, K., \& Harris, L. (2001). Symptoms research: A fertile field. Annals of Internal Medicine, 134, 801-802.

Kroenke, K., \& Laine, C. (Eds.) (2001). Investigating symptoms: Frontiers in primary care. Supplement to Annals of Internal Medicine, 134, 2.

Kroenke, K., \& Mangelsdorff, D. (1989). Common symptoms in ambulatory care: Incidence, evaluation, therapy, and outcome. American Journal of Medicine, 86, 262-266.

Lipsitt, D. R. (1970). Medical and psychological characteristics of "crocks." International Journal of Psychiatric Medicine, 1, 15-25.

Martin, P. A. (1975). The obnoxious patient, tactics and techniques in psychoanalytic therapy. In P. L.Giovacchinil (Ed.), Countertransference (Vol. 2; pp. 196-204). New York, NY: Jason Aronson.

Matthews, E. H. (2004). Merleau-Ponty's body-subject and psychiatry. International Review of Psychiatry, 16, 190-198.

McDaniel, S. H., Hepworth, J., \& Doherty, W. J. (1992). Medical family therapy: A biopsychosocial approach to families with health problems. New York: Basic Books.
Morgan, D. (Ed.) (1993). Successful focus groups: Advancing the state of the art. Newbury Park, CA: Sage.

Orfali, K., \& Anderson-Shaw, L. (2005). When medical cure is not an unmitigated good. Perspectives in Biology and Medicine, 48, 282-292.

Patterson, J., Peek, C. J., Heinrich, R. L., Bischoff, R. J., \& Scherger, J. (2002). Mental health professionals in medical settings: A primer. New York: Norton.

Peters, M., Abu-Sad, H. H., Vydelingum, V., Dowson, A., \& Murphy, M. (2004). Migraine and chronic daily headache management: A qualitative study of patients' perspective. Scandinavian Journal of Caring Sciences, 18, 294-303.

Schwenk, T. L., \& Romano, S. E. (1992). Managing the difficult physician-patient relationship. American Family Physician, 46, 1503-1510.

Seaburn, D. B., Lorenz, A. D., Gunn, W. B., Gawinski, B. A., \& Mauksch, L. B. (1996). Models of collaboration: A guide for mental health professionals working with health care practitioners. New York: Basic Books.

Sharpe, M., Mayou, R., Seagroatt, V., Surawy, C., Warwick, H., Bulstrode, C., et al. (1994). Why do physicians find some patients difficult to help?Quarterly Journal of Medicine, 87, 187-193.

Strauss, A., \& Corbin, J. (1998). Basics of qualitative research. Newbury Park, CA: Sage.

Stuart, M. R., \& Lieberman, J. A. (2002). The fifteen minute hour: Practical therapeutic interventions in primary care. Philadelphia: Saunders.

Suchman, A. L., Roter, D., Green, M., Lipkn, M., \& Collaborative Study Group of the American Academy on Physicians and Patient (1993). Physician satisfaction with primary care office visits. Medical Care, 31, 1083-1092.

Wagner, P. J., \& Hendrich, J. E. (1993). Physician views on frequent medical use: Patient beliefs and demographic and diagnostic correlates. The Journal of Family Practice, 36, 417-422.

Walker, E. A., Unutzer, J., \& Katon, W. J. (1998). Understanding and caring for the distressed patient with multiple medically unexplained symptoms. Journal of the American Board of Family Practice, 11, 347-356. 